\title{
Ser professor de gaita-ponto no projeto fábrica de gaiteiros: um estudo de caso
}

\author{
Antonio Cezar Ferreira
}

Universidade Federal do Rio Grande do Sul, Brasil

DOI: https://doi.org/10.31492/2184-2043.RILP2020.37/pp.191-203

\section{Resumo}

Este artigo trata de compreender os modos como professores de gaita-ponto que atuam no projeto Fábrica de Gaiteiros, se formaram, identificando especificidades presentes na sua formação músico-pedagógica. O estudo de caso foi adotado como metodologia (Fonseca, 2002; Gomes, 2008; Passeron \& Revel, 2005; Yin, 1994). Esta pesquisa alinha-se com a sociologia da educação musical e tem como referenciais teóricos autores que discutem a importância da trajetória pessoal e profissional na formação dos professores (Isaia, 2008, 2009; Nóvoa, 1995, 2007, 2012, 2017). Os resultados revelaram que o projeto Fábrica de Gaiteiros funciona em termos contextuais como um guarda-chuva sob o qual os professores que participam da presente pesquisa desenvolvem na interação uma pedagogia própria voltada para o instrumento. O trabalho contribui para uma visão mais ampla acerca da formação e atuação do professor de gaita-ponto e para repensar a carreira do professor no contexto da formação acadêmica em música.

Palavras-chave: formação de professores; professores de acordeom; profissão professor.

\section{Abstract}

This study introduces a master's research, finished in 2019, which pursued to understand the ways in which diatonic accordion teachers working in the Fábrica de Gaiteiros project were formed, identifying specific characteristics present in their musico-pedagogical training. The case study was adopted as a methodology (Fonseca, 2002; Gomes, 2008; Passeron \& Revel, 2005; Yin, 1994). This research is aligned with the sociology of music education and has as theoretical references authors who discuss the importance of personal and professional trajectory in teacher training (Isaia, 2008, 2009; Nóvoa, 1995, 2007, 2012, 2017). The results revealed that the Fábrica de Gaiteiros project works in contextual terms as an umbrella under which the teachers who participate in this research develop in their interaction a pedagogy of their own that is focused on the instrument. The work contributes to a broader view of the formation and performance of the diatonic accordion teacher and to rethink the teacher's career in the context of academic training in music.

Keywords: teachers; training of teachers; teacher profession.

\section{Introdução}

Este artigo versa sobre os modos de ser professor de gaita-ponto no projeto Fábrica de Gaiteiros, que foram estudados, em 2018, durante a pesquisa de mestrado do autor desse artigo (Ferreira, 2019). Esse projeto tem como foco central o ensino de gaita-ponto para crianças e jovens de sete a quinze anos de idade nos estados do Rio Grande do Sul e Santa Catarina, no sul do Brasil e foi criado, em 2009, pelo músico Renato Borghetti ${ }^{1}$. Além do enfoque pedagógico-musical o projeto dedica-se também à confecção própria de instrumentos.

1. Renato Borghetti, acordeonista e compositor de Porto Alegre/Brasil, ganhador de vários prêmios, entre eles, em 1991, o prêmio disco do ano, na categoria regional, da Associação Paulista de Críticos de Arte do estado de São Paulo/Brasil. 
A gaita-ponto, instrumento aerófono, pertence à família dos acordeons. Além da gaita-ponto, pertence a essa família o acordeom de teclas, também conhecido por acordeom a piano ou gaita a piano. $\mathrm{O}$ modelo de acordeom diatônico com duas fileiras de botões para a mão direita e oito botões para a mão esquerda é conhecido na região Sul do Brasil como gaita-ponto e na região Nordeste do Brasil como sanfona de oito baixos. Na Europa, há outras denominações para esse instrumento, como acordeon diatonic (França), organeto (Itália) ou diatonisches Akkordeon (Alemanha). Em Portugal, a gaita-ponto é mais conhecida por concertina. A principal característica deste instrumento é a sonoridade dupla (bissonoridade) para cada botão. Assim, um mesmo botão emite notas diferentes se o fole é aberto ou fechado. Sendo assim, a técnica da gaita-ponto difere bastante do acordeom de teclado.

Diante do fechamento das principais fábricas de acordeom no Brasil nas décadas de 1980 e 1990, as únicas gaitas-ponto disponíveis no mercado brasileiro eram as usadas que tinham que ser restauradas a alto custo. É nesse cenário que surge a Fábrica de Gaiteiros com o objetivo do ensino da gaita-ponto e a confecção própria de instrumentos, diante das solicitações de doação de gaitas ou auxílio para aquisição do instrumento.

Na época da realização da pesquisa, em 2018, o projeto Fábrica de Gaiteiros contava com onze unidades, nove no estado do Rio Grande do Sul e duas no estado de Santa Catarina, no sul do Brasil. No Rio Grande do Sul, as unidades estão localizadas nos municípios de Porto Alegre (duas unidades), Guaíba, Barra do Ribeiro, Butiá, Tapes, São Gabriel, Bagé, Lagoa Vermelha. Em Santa Catarina, as unidades estão localizadas em Lages e Blumenau. No período da pesquisa, o projeto atendia a aproximadamente quinhentas crianças e jovens, entre sete e quinze anos, e contava com onze professores - cada unidade tem um professor que é também o administrador da unidade. Além das aulas regulares, em cada unidade, os professores têm dois encontros anuais, com todos os participantes, realizados na sede do projeto, em Barra do Ribeiro.

As aulas são gratuitas e o projeto conta com dois patrocinadores: Celulose Riograndense e Thyssen Krupp. Os instrumentos são produzidos na sede do projeto, em Barra do Ribeiro, e são emprestados aos alunos para o estudo, a exemplo do que ocorre em bibliotecas com livros. O projeto possui um método para gaita-ponto concebido especialmente para o projeto, porém não é obrigatória a utilização desse material pelos professores, podendo ser utilizado como referência para o repertório estudado pelos alunos.

Durante o período em que fazem parte do projeto Fábrica de Gaiteiros, os alunos participam de diversas apresentações musicais a convite de instituições públicas e privadas, muitas delas ao lado do mentor do projeto, Renato Borghetti. 
Após ter contato com o projeto Fábrica de Gaiteiros, surgiram alguns questionamentos: Como são escolhidos os professores que atuam nesse projeto? Como se formaram esses professores? Quando começaram a dar aulas de gaita-ponto? E de onde vem o conhecimento necessário para ministrar essas aulas?

A partir desses questionamentos, propus a realização da pesquisa de mestrado com os seguintes objetivos: Objetivo Geral: Compreender os modos de ser professor de gaita-ponto no projeto Fábrica de Gaiteiros. Objetivos Específicos: Compreender como professores de gaita-ponto que atuam no projeto Fábrica de Gaiteiros se formaram; identificar especificidades presentes na sua formação músico-pedagógica; analisar as particularidades de suas experiências como professores de gaita-ponto no projeto Fábrica de Gaiteiros; identificar sua percepção em relação à sua atuação profissional nesse projeto.

\section{Metodologia}

A metodologia escolhida para a pesquisa foi o estudo de caso com auxílio de entrevistas semiestruturadas. O grupo de colaboradores desta pesquisa é formado pelo administrador do projeto, e por cinco professores de gaita-ponto que atuam nas unidades situadas nas cidades de: Porto Alegre, Guaíba, Barra do Ribeiro, Butiá e Bagé, todas no estado do Rio Grande do Sul, Brasil.

Os professores participantes do estudo são: Eduardo Vargas, Fofa Nobre, Renato Müller, Adriana de Los Santos e Augusto Maradona. Esses professores possuem entre dez e vinte e sete anos de experiência como professor particular de gaita-ponto, e iniciaram a atuação no projeto Fábrica de Gaiteiros entre março de 2011 e outubro de 2014. O administrador do projeto é Newton Grande e atua nessa função desde 2009.

Para compreender os modos de ser professor nesse espaço é necessário compreender também a estrutura e a organização do projeto. Para isso elaborei dois roteiros de questões, um para o administrado, outro para os professores que atuam no projeto.

O roteiro para a entrevista com os professores de gaita-ponto foi organizado em quatro grandes partes: percursos de formação musical, atuação como professor de gaita-ponto, atuação dos professores no projeto Fábrica de Gaiteiros e reflexões sobre o ser professor de gaita-ponto. Para elaboração do roteiro, foram observados três eixos escolhidos para a organização dos dados desta pesquisa: formação, atuação e reflexões sobre o ser professor. Realizei então seis entrevistas incluindo o administrador do projeto e cinco professores, gerando seis horas e cinquenta e nove minutos de gravação de áudio e vídeo, que geraram cento e sessenta páginas de transcrição.

Todos os professores concederam a autorização para a utilização da entrevista registrando sua concordância oralmente, estando este registro gravado e arquivado 
na residência do pesquisador. $\mathrm{O}$ administrador do projeto, Newton Grande, concedeu a autorização por e-mail.

Como mencionado anteriormente, o roteiro de questões para os professores foi dividido em quatro grandes partes. Essas partes deram origem, mais tarde, aos quatro capítulos de análise da dissertação. Para auxiliar na caracterização das entrevistas, o roteiro foi transformado em sumário. Após a transcrição das entrevistas, as mesmas foram organizadas em um Caderno de Entrevista e divididas em fragmentos temáticos que foram relacionados com os tópicos que constavam no sumário. Como resultado, obtive um documento de cento e sessenta e sete páginas. Após a tematização e organização dos fragmentos temáticos, foi feita a redação do texto, transformando as entrevistas em narrativas para sua análise qualitativa, considerando os três eixos analíticos desta pesquisa, como mencionado: formação, atuação e reflexões sobre o ser professor.

\section{Referencial teórico}

Respaldado pela sociologia da educação musical e pelas teorias do cotidiano, adotei como referencial teórico ideias do educador português Antonio Nóvoa sobre a formação de professores. Nóvoa traz uma contribuição importante para a minha pesquisa no sentido da discussão da constituição do professor a partir da sua trajetória pessoal e profissional como referência para se pensar a formação de professores.

"Como é que uma pessoa aprende a ser, a sentir, a agir, a conhecer e a intervir como professor?" (Nóvoa, 2017, p. 1113). A forma como o professor reage a um contratempo, por exemplo, é uma lição que ele tira da ação praticada com a qual ele constrói seu saber docente. Para Nóvoa,

\footnotetext{
A formação não se constrói por acumulação de cursos, conhecimentos e técnicas, mas sim, através de um trabalho de reflexividade crítica sobre práticas e de reconstrução permanente da identidade pessoal. Por isso é tão importante investir a pessoa e dar um estatuto ao saber da experiência (NÓVOA, 1995 , p. 25).
}

Nóvoa corrobora a afirmação de Pierre Dominicé de que "a vida é o lugar da educação e a história de vida o terreno no qual se constrói a formação". É a partir da "própria reflexão daqueles que se formam" que se constitui a formação (Dominicé, 1990, apud Nóvoa, 1995, p. 24). Esse autor destaca ainda a afirmação de Jennifer Nias de que"o professor é a pessoa; e uma parte importante da pessoa é o professor" (Nias, 1991, apud Nóvoa, 1995, p. 15).

De forma semelhante, Isaia (2009) enfatiza que a forma como cada professor exerce a docência vai depender da pessoa que ele é, e o seu jeito como pessoa 
reflete no seu modo de ser professor. "Por que fazemos o que fazemos em sala de aula?" (Nóvoa, 1995, p.16). São as nossas preferências, as nossas vivências e até mesmo a forma como reagimos a casualidades que consolidam o nosso jeito, o comportamento que nos identifica como professores. É a forma como cada um planeja suas aulas, a maneira de agir com os alunos, o jeito de desenvolver e utilizar materiais didáticos que concebem a nossa "segunda pele profissional" (Nóvoa, 1995, p.16), e no caso da minha pesquisa, os modos de ser professor de gaita-ponto no projeto Fábrica de Gaiteiros.

\section{Revisão bibliográfica}

Após a análise de vários trabalhos relacionados ao acordeom apresentados a seguir, notei que a pesquisa em educação musical, no que tange ao ensino e à aprendizagem do acordeom no Brasil, carece de um maior aprofundamento.

Entre os trabalhos acadêmicos com o intuito de investigar o estudo do acordeom encontrei as pesquisas de Cordeiro (2016), Weiss (2015), Paiva (2014), Borba (2013), Pereira e Nascimento (2013), Guimarães Júnior e Sousa (2012), Puglia (2010), Silva (2010), Machado (2009) e Zanatta (2005).

A pesquisa de Weiss (2015) trata da formação de professores que não possuem habilitação específica para lecionar o instrumento. Weiss aborda os caminhos formativos de professores de acordeom de diferentes cidades do Rio Grande do Sul, por meio da análise de suas histórias de vida, contadas através de narrativas.

Guimarães Júnior e Sousa (2012) investigam em seu trabalho sobre a transmissão, o aprendizado e a difusão da música instrumental executada por sanfoneiros no Triângulo Mineiro², de 1950 a 1990, "os processos vivenciados por tocadores de acordeom, evidenciando características tradicionais, costumes e sociabilidades que possibilitem reconstruir aspectos da história de músicos, da música e do aprendizado tradicional" (Guimarães Júnior e Sousa, 2012, p. 190).

Ponto de convergência entre as pesquisas de Weiss (2015) e Guimarães Júnior e Sousa (2012) é o fato de que, em algumas das falas dos entrevistados, o acordeom aparece como legado musical da família. Essa informação é confirmada nos relados dos professores que participam da minha pesquisa.

Pereira e Nascimento (2013, p. 73) em seu artigo "O acordeom na educação musical: perspectivas para uma formação inicial no ensino superior" investigam a "formação do educador musical no contexto do curso de Licenciatura em Música e em um instrumento específico, neste caso acordeom", e analisam "as especificidades de formação do professor de instrumento, sobre as habilidades, saberes e competências necessárias" (p. 74).

2. Região do estado de Minas Gerais, no sudeste do Brasil. 
Trabalhos acadêmicos que tratam do ensino e da formação de professores de outros instrumentos também fizeram parte da minha revisão bibliográfica, como as pesquisas de Bozzetto (1999), Vieira (2009) e Weber (2014).

Vieira (2009) que investiga a prática profissional de oito professores de violão, que exercem sua atividade em Porto Alegre/RS, busca em sua dissertação de mestrado "apreender e compreender os aspectos constitutivos da cultura profissional dos professores de violão, o conjunto de valores, atitudes, interesses, destrezas e conhecimentos próprios daqueles que ministram aulas desse instrumento" (Vieira, 2009, p. 11).

Vieira (2009) e Weiss (2015) concordam quando concluem que os professores de instrumento constituem "um grupo social singular que compartilha aspectos de uma cultura profissional, que é transmitida no transcorrer da socialização profissional" (Vieira, 2009, p. 15).

Bozzetto (1999) discute as práticas e trajetórias profissionais de treze professores particulares de piano, a partir de suas narrativas. A autora mostra que esses professores possuem concepções claras sobre a profissão e estão atentos às mudanças que foram ocorrendo durante os anos de trajetória docente, de forma semelhante aos professores de gaita-ponto, colaboradores desta pesquisa, desmistificando a ideia de que o professor particular está descomprometido com seu papel como profissional. Segundo Bozzetto (1999) esses professores atuam "indo ao encontro das necessidades do aluno em aprender música, avaliando e reajustando suas formas de ver e de proceder" (Bozzetto, 1999, p. viii).

A pesquisa de Weber (2015) teve como objetivo compreender o processo de construção da docência de instrumentistas bacharéis que atuam como professores de instrumento, assim como compreender seus processos formativos e investigar os saberes que esses professores mobilizam na docência do instrumento. Weber $(2015$, p. 130) concluiu é por meio da formação, das vivências junto a professores e colegas, e da experiência com a prática pedagógica que os saberes mobilizados para torna-se docente-bacharel são integrados ao ser professor.

Puglia (2010) discute em sua pesquisa as características do ensino do acordeom no Brasil e a situação em que se encontra na atualidade, abordando os processos de ensino do instrumento juntamente com análises de material didático. Machado (2009) investiga práticas pedagógicas de dois professores particulares de acordeom, com a finalidade de desvendar aspectos relevantes e marcantes das suas atuações como docentes. Ponto comum nas pesquisas de Weiss (2015), Pereira e Nascimento (2013), Puglia (2010) e Machado (2009) é a crítica quanto à escassez de pesquisas sobre o ensino de acordeom no Brasil. 
A revisão de literatura cumpriu seu objetivo de revelar aspectos importantes da formação dos professores de acordeom tais como o acordeom como legado musical da família, a existência de um possível conflito identitário como consequência das múltiplas atividades exercidas pelo artista-professor, assim como a confluência dos diversos processos de aprendizagem. Nos tópicos a seguir serão apresentados alguns resultados da pesquisa.

\title{
5. Resultados
}

\subsection{Percursos de formação}

O legado musical em família apareceu com grande força nos depoimentos dos professores entrevistados. Eles tiveram seu primeiro contato com um instrumento musical através de um familiar. Entre esses familiares havia músicos amadores e, também, profissionais.

\begin{abstract}
Augusto Maradona: Eu venho de uma família de músicos. Eram tocadores de bandoneom, bandoneom crioulo, não o uruguaio, argentino, bandoneom daqui mesmo. O meu bisavô, muito famoso aqui na região, como homeopata e animador de baile: Nonô Freitas. Ele tinha um salão de baile (FERREIRA, 2019, p. 68).
\end{abstract}

A aprendizagem através da observação de outros músicos é destacada nos depoimentos ouvidos. Por meio das vivências junto a colegas, os professores elaboram seus conhecimentos sobre a escolha do repertório, a técnica aplicada à gaita-ponto, entre outros aspectos da aprendizagem desse instrumento.

A utilização das mídias como fitas K-7 e discos de vinil na aprendizagem da gaita-ponto é considerada pela maioria dos professores como essencial. Enquanto, no início da aprendizagem, o rádio era importante fonte de informação na formação do repertório, hoje os professores recorrem à internet para manterem-se atualizados.

Fofa Nobre: Era no toca-fita. Eu ligava para rádio, pedia a música. Eu quero ouvir a música "Madrugada”. Aí eles tocavam na Rádio Liberdade. Eu saía correndo, porque eu não tinha telefone em casa. Saía correndo, ia pra casa, preparar a fita. Quando tocava, eu gravava. Não era essa facilidade de hoje. Hoje tem o celular, tem o CD, tem o youtube. Tá tudo na mão ali (Ferreira, 2019, p. 65).

Uma tônica em muitos depoimentos dos professores é o fato de que o estudo da gaita-ponto era realizado de forma difusa na primeira fase de aprendizado. Eram aprendizagens sem saber que se estava aprendendo. Renato Müller que aprendia com o irmão a tocar gaita-ponto, relata: "Chegou um dia em que eu, do nada, peguei a gaita, e tudo aquilo que ele [o irmão] tentava me ensinar, eu sentei e toquei, sem...tipo assim, eu aprendi dormindo, sabe" (Ferreira, 2019, p. 59). 
Ponto de convergência na trajetória profissional dos professores entrevistados é o fato de terem alguma relação de aprendizagem com o músico Sadi Cardoso que viveu na cidade de Guaíba, no Rio Grande do Sul, e atuou como professor de gaita-ponto na região metropolitana de Porto Alegre, nos anos 1990. Motivados também pela proximidade geográfica, quatro dos cinco professores entrevistados foram alunos de Sadi Cardoso, ou tiveram como referência um músico que foi aluno desse professor.

\subsection{Atuação como Professor}

A atividade docente é iniciada pela maioria dos professores entrevistados de forma não planejada, motivada por necessidades financeiras. Entre os primeiros alunos, estão pessoas próximas, como amigos, colegas e conhecidos em geral. Mais tarde, esses professores descobriram o gosto por ensinar e a demanda por aulas passou a representar uma possibilidade concreta de aquisição renda, na área da música. Na visão de Fofa Nobre: "Tu vê, né. Não sei. Um dia eu tava lá em casa brincando, daqui a pouco eu já tava tocando, daqui a pouco já sou professora. Foi tudo muito sem querer. Sério" (Ferreira, 2019, p. 96). Para seu colega Renato Müller: "Na realidade, eu não sabia que eu ia acabar gostando de dar aula. A minha [atuação como professor de gaita-ponto] surgiu, como eu falei antes, extremamente da necessidade. Necessidade, financeira. Financeira mesmo. E ali eu descobri que eu gostava" (Ferreira, 2019, p. 94).

No início da atuação docente, os professores não se percebem como professores. É através das suas experiências que vão vestindo a "segunda pele profissional", conceito usado por Nóvoa.

É notável nos depoimentos dos professores como a concepção de uma metodologia, de um jeito de dar aula de gaita-ponto, vai acontecendo com o tempo advindo da prática reflexiva - reformulando o que já foi realizado e o que está sendo feito no momento. Segundo Eduardo Vargas: "Eu tive que começar a aprender pra poder ensinar a mão direita. Aí eu comecei a estudar a questão da digitação e a função de cada afinação" (Ferreira, 2019, p. 100).

Eu pergunto ao professor Renato Müller: "Tu poderias dizer que tu fostes te descobrindo professor de gaita-ponto no ato?" Ele responde: "No ato, no ato. Ali também, através do dar aula. O menino não está conseguindo, como é que eu vou fazer pra ele entender?" (Ferreira, 2019, p. 99).

Os professores buscam aperfeiçoamento, especialmente no domínio técnico da gaita-ponto, em workshops e aulas particulares. A participação em festivais, conhecidos no sul do Brasil como Rodeios, representa para os professores uma 
plataforma para troca de experiências, assim como está associada ao reconhecimento desses músicos como profissionais.

Na visão de Adriana de Los Santos: "O rodeio contribui porque te incentiva, e tu começas a ver os outros, o jeito dos outros tocarem, como é que os outros estão tocando, que eles estão melhores que tu, e começas a aprender também" (Ferreira, 2019, p. 110).

\subsection{Atuação no projeto Fábrica de Gaiteiros}

Por estar situado em diferentes regiões, ter diferentes apoios, as unidades do projeto Fábrica de Gaiteiros têm condições institucionais diferenciadas de trabalho. Embora o projeto tenha uma administração central, não possui um prédio onde estão abrigados todos os alunos e professores. Dessa forma, são múltiplas as funções desenvolvidas pelos professores de gaita-ponto.

Na visão de Fofa Nobre, ela desempenha várias funções: Secretária, faxineira, professora, psicóloga, pedagoga, e tudo mais. Mãe. Tudo aqui (Ferreira, 2019, p. 41). Augusto Maradona relata que desempenha as seguintes funções: Professor de gaita, babá, faxineira, secretário, coordenador, psicólogo, amigo, criança. Tudo, tudo. (Ferreira, 2019, p. 141).

Os professores investigados são músicos que começaram a se dedicar ao ensino mais fortemente a partir do projeto Fábrica de Gaiteiros. Eles foram convidados a participar do projeto pelo seu criador, Renato Borghetti, por serem músicos, não professores. Esses músicos já davam aulas antes, mas decidiram investir mais na área do ensino a partir da atuação no referido projeto. A consolidação da atividade docente ocorre através do projeto Fábrica de Gaiteiros que impulsiona também a procura de alunos particulares. Segundo Eduardo Vargas: Porque daí com a questão de eu dar aula no projeto, acabei ficando conhecido como professor e pela metodologia. E começaram a vir me procurar em casa pra dar aula particular. Dali pra cá, triplicou o número de alunos particulares (Ferreira, 2019, p. 94).

A figura de Renato Borghetti como mentor do projeto aparece como elemento positivo nas narrativas dos professores. Por ser um músico conhecido, Renato Borghetti contribui para a motivação e para o comprometimento das crianças e jovens com as aulas de música.

Na visão de Adriana de Los Santos, isso acontece "porque é um projeto diferente. Porque ele transmite acho que mais segurança de tu trabalhares. Em razão do quê? Envolve o nome de uma pessoa que é um ícone, que é o Renato Borghetti. Eu acho que com isso as crianças já vêm, aqueles que vêm interessados pra 
aula, eles já vêm com um objetivo maior, porque eles já têm um ícone ali. Facilita para o trabalho" (Ferreira, 2019, p. 178).

A concepção de que o professor de música deve dominar a notação musical e que o aprendizado musical com o uso da partitura é algo superior em detrimento àquele transmitido via oralidade é recorrente nos depoimentos dos professores. Essa postura contradiz a experiência positiva com a oralidade obtida pelos professores na sua formação como músicos profissionais.

Em virtude de os conhecimentos sobre a prática da gaita-ponto serem transmitidos via oralidade, especialmente no Brasil, o professor de gaita-ponto muitas vezes é estigmatizado pelo senso comum como o professor que ensina informalmente, sem metodologia, classificando sua prática como inferior a outras formas de ensino/aprendizagem musical. A prática musical no projeto Fábrica de Gaiteiros, no qual a maioria das crianças e jovens aprende música pela imitação, pode ajudar a rever a crença de que a oralidade é algo inferior, e mostrar que: "Os músicos que não leem partitura não são incultos, e o uso da partitura não significa um caminho mais nobre para o aprendizado musical” (Souza, 2011, p. 212).

\subsection{Reflexões sobre o Ser Professor}

Os professores descrevem a satisfação profissional associada a experiências em que puderam ajudar os alunos a vencer crises pessoais. A confiança e a amizade associada à relação professor/aluno aparecem com grande força nos depoimentos ouvidos. Conforme Augusto Maradona:

Porque, às vezes, o cara tá cansado, o cara tá com dor de cabeça, o cara brigou com a namorada, o cara atrasou o salário. E chega lá, com quase cinco anos, no quinto ano da Fábrica em Bagé [Rio Grande do Sul], eu chego ali, tem dias que eu tenho dia ruim, mas noventa por cento dos dias liga a coisa boa, assim. Liga. Estão ali os meus alunos, e acima de tudo, estão ali os meus amigos (Ferreira, 2019, p. 157).

Entretanto, os professores concordam no sentido de que no âmbito dessa amizade, o professor deve manter uma posição firme, ser compreensivo, mas exigente com o aluno, mostrando os limites entre amizade e docência. Para Eduardo Vargas: "Então, tem as brincadeiras, nas aulas coletivas, volta e meia termina com um cafezinho. Mas eu sou muito rígido na hora de estudar. Libero pra brincadeiras, é óbvio, tem as brincadeiras, tem as arriações, mas quando o assunto é sério, é sério" (Ferreira, 2019, p. 152).

A pesquisa mostra ainda que a consolidação da atividade docente através do projeto permite ao professor um aprimoramento e um planejamento da sua carreira. Entre os planos para o futuro mencionados pelos professores está investir na área da docência em música e na formação continuada de professor. Renato Müller, não 
pretende interromper a atividade de professor de gaita-ponto. Perguntado se consegue se imaginar mais dez anos atuando no projeto Fábrica de Gaiteiros e talvez a vida toda dando aula, ele responde enfaticamente que sim (Ferreira, 2019, p. 181).

\section{Conclusões}

Pelos depoimentos dos professores, observa-se que:

Não existe uma única forma de se tornar professor, de construir-se professor, de aprender a docência. Cada professor de gaita-ponto desenvolveu sua própria metodologia pautada na experiência. $\mathrm{O}$ instrumento gaita-ponto e o projeto modificam as formas de ser professor de música. O projeto Fábrica de Gaiteiros funciona em termos contextuais como um guarda-chuva sob o qual os professores que participaram desta pesquisa desenvolvem na interação uma pedagogia própria voltada para o instrumento.

Ser professor de gaita-ponto no projeto Fábrica de Gaiteiros significa estar em sintonia com a comunidade. Esse aspecto é notado nas relações de proximidade desenvolvidas entre professor e aluno nesse projeto. A preocupação dos professores de gaita-ponto em ir ao encontro das necessidades do aluno ultrapassa a esfera da aula de música. Os professores entrevistados estabelecem relações de confiança e amizade e se dispõe a ajudar aos alunos em questões que surgem fora da sala de aula. Como aponta Souza, “...a aprendizagem não se dá num vácuo, mas num contexto complexo. Ela é constituída de experiências que nós realizamos no mundo" (Souza, 2016, p.7).

O professor de gaita-ponto dificilmente aparece no quadro de professores das escolas de música particulares, sendo totalmente ausente no ensino de música regular, embora o instrumento gaita-ponto esteja presente na cultura popular de vários estados brasileiros, particularmente nas regiões sul, sudeste e nordeste. Os relatos coletados e a análise realizada nesta pesquisa contribuem para a legitimidade e dignidade do professor de gaita-ponto. Os professores de gaita-ponto entrevistados desempenham importante papel na área de ensino de música nas comunidades em que estão inseridos. Sua contribuição na educação musical e na formação de crianças e jovens não é menos importante do que a dos professores que tem uma formação institucionalizada.

Observa-se, no relato dos colaboradores que o ensino da gaita-ponto ocorre por processos de autoaprendizagem e fora das instituições escolares. Desvendar especificidades do ser professor no projeto Fábrica de Gaiteiros pode contribuir para compreender as estratégias que se utilizam para a manutenção do ensino e aprendizagem de um instrumento como a gaita-ponto. Assim, revelar as histórias de formação dos professores de gaita-ponto pode lançar um novo olhar para a 
pedagogia do acordeom e seu potencial nos diversos espaços de atuação da educação musical. Por fim, a pesquisa pode contribuir para a compreensão dos caminhos do ser professor na área de música e para repensar a carreira do professor no contexto da formação acadêmica em música.

\section{Referências}

Borba, Ronison Elias. (2013). Ensino de acordeom no Rio Grande do Sul: Breve análise de quatro métodos 2013, 66 p. (Monografia de Conclusão de Curso Licenciatura em Música). Universidade Federal de Santa Maria, Santa Maria.

Bozzetto, Adriana. (1999). O professor particular de piano em Porto Alegre: uma investigação sobre processos identitários na atuação profissional (Dissertação de Mestrado). Universidade Federal do Rio Grande do Sul, Porto Alegre.

Cordeiro, Josimar José. (2016). Orquestra de Acordeon de Luiz Alves: experiências de aulas de acordeon em grupo (Monografia de Conclusão de Curso Especialização em Música). Universidade do Vale do Itajaí, Itajaí.

Ferreira, Antonio C. (2019). Ser professor de gaita-ponto no projeto Fábrica de Gaiteiros: um estudo de caso (Dissertação de Mestrado em Música). Universidade Federal do Rio Grande do Sul, Porto Alegre.

Fonseca, João José Saraiva da (2002). Metodologia da pesquisa científica. Fortaleza: UEC.

Gomes, Alberto Albuquerque (jan./dez. 2008). Estudo de caso - planejamento e métodos. Nuances: estudos sobre Educação, 15(16), 215-221.

Guimarães Júnior, A. C.; Sousa, J. J. M. (nov. 2012). Transmitir, aprender e difundir: O acordeom no pontal do Triângulo Mineiro, 1950-1990. In Flavio José Gomes Cabral (Org.), Anais Eletrônicos do VI Colóquio de História "Faces da Cultura na História: 100 anos de Luiz Gonzaga" (p. 187-193). Recife.

Isaia, Silvia Maria Aguiar (2008). Aprendizagem docente: sua compreensão a partir das narrativas de professores. In Traversini, C.; Eggert, E.; Bonin, I. (Org.), Trajetórias e processos de ensinar e aprender: práticas e didáticas (p. 618-635). Porto Alegre: EduPUCRS.

Isaia, Silvia Maria de Aguiar (2009). Na tessitura da trajetória pessoal e profissional: a constituição do professor do ensino superior. In Sílvia Maria Aguiar Isaia; Dóris Pires Vargas Bolzan; Adriana Moreira da Rocha Maciel (Org.), Pedagogia Universitária: Tecendo redes sobre a educação superior (p. 95-106). Santa Maria: Ed. da UFSM.

Machado, André Vargas. (2009). Ensino de acordeon: um estudo a partir da prática docente de dois professores (Monografia de Conclusão de Curso Licenciatura em Música). Universidade Estadual do Rio Grande do Sul, Montenegro.

Nóvoa, Antonio (1995). Os professores e as histórias da sua vida. In Nóvoa, Antonio (Org.), Vidas de professores (p. 11-30). 2. ed. Porto: Porto.

(set./dez. 2007). Os lugares da teoria e os lugares da prática da profissionalidade docente. Revista Educação em Questão, 30(16), 197-205. 
(jan./jun. 2012). Devolver a formação de professores aos professores. Cadernos de Pesquisa em Educação, 18(35), 11-22.

(out./dez. 2017). Firmar a posição como professor, afirmar a profissão docente. Cadernos de Pesquisa, 47 (166), 1106-1133.

Paiva, Cláudio Nóbrega de. (2014). Uma experiência de ensino do acordeon na Escola de Música da UFRN (Monografia de Conclusão de Curso Licenciatura em Música). Universidade Federal do Rio Grande do Norte, Natal.

Passeron, Jean-Claude; Revel, Jacques (2005). Penser par cas: raisonner à partir de singularités. In Passeron, Jean-Claude \& Revel, Jacques (Org.), Penser par cas (p. 9-44). Paris: Enquête.

Pereira, Júlio Cesar P.; Nascimento, Flávia M. (jul./dez. 2013). O acordeom na educação musical: perspectivas para uma formação inicial no ensino superior. Revista da Fundarte, 13(26), 73-89.

Puglia, Eduardo Faleiros. (2010). O ensino do acordeom na região sudeste do Brasil (Monografia de Conclusão de Curso Licenciatura em Música). Universidade de Ribeirão Preto, Ribeirão Preto.

Souza, Jusamara (2016). Aprender e ensinar música no cotidiano: pesquisas e reflexões. In Souza, Jusamara (Org.), Aprender e ensinar música no cotidiano (p.7-13). 2. ed. Porto Alegre: Editora Sulina.

Souza, Jusamara (2011). Sobre as múltiplas formas de ler e escrever música. In Neves, Iara Conceição Bitencourt...[et al.] (Org.), Ler e escrever: compromisso de todas as áreas (p. 209-220). 9. ed. Porto Alegre: UFRGS Editora.

Vieira, Alexandre (2009). Professores de violão e seus modos de ser e agir na profissão: um estudo sobre culturas profissionais no campo da música (Dissertação de Mestrado em Música). Universidade Federal do Rio Grande do Sul, Porto Alegre.

Weber, Vanessa (2004). Tornando-se professor de instrumento: narrativas de docentes-bacharéis (Dissertação de Mestrado). Universidade Federal de Santa Maria, Santa Maria.

Weiss, Douglas (2015). A formação de professores de acordeom do Rio Grande do Sul: narrativas (auto)biográficas (Dissertação de Mestrado). Universidade Federal de Santa Maria, Santa Maria.

Yin. Robert K. (1994). Pesquisa Estudo de Caso - desenho e métodos (2 ed.). Porto Alegre: Bookman.

(2005). Estudo de caso: planejamento e métodos. Porto Alegre: Bookman.

Zanatta, Maria Aparecida Fabri. (2005). Dialetos do acordeão em Curitiba: Música, cotidiano e representações sociais. (Dissertação de Mestrado). Universidade Estadual de Ponta Grossa, Ponta Grossa. 